\title{
ORIGINAL RESEARCH

COMPARISON OF PROPRIOCEPTION IN INJURED
AND UNINJURED KNEE JOINTS AMONG MALE
PROFESSIONAL FOOTBALLERS

\author{
${ }^{1}$ Jibi Paul \\ ${ }^{2}$ Dr. M S Nagarajan
}

\section{ABSTRACT}

Back ground: Football is one of the most popular sports in the world. There are over 240 million registered players worldwide and many more recreational footballers. The knee is a complex joint with many components making it vulnerable to a variety of injuries. The study has investigated the effect of knee proprioception error on injured and uninjured male professional footballers.

Methods: This was a cross sectional comparative study with hundred and six (106) male professional footballers were selected for the study as per the selection criteria. Hundred and eighteen injured and ninety four uninjured knee samples were analysed for this study. Photographic analysis method was used to evaluate proprioception error at inner, middle and outer range of knee joint. Proprioception error of knee joint was measured at inner range, middle range and outer range for injured and uninjured groups. Data analysis found that there is significant difference in proprioception error between the groups.

Result: Comparative study was performed using independent t' test for proprioception error between knee injured and uninjured groups. $\mathrm{P}<0.05$ were considered as significant difference in effect for this study. The mean of knee injured and uninjured groups were 6.08 and 5.55 respectively with $t^{\prime}$ value 2.21 and degree of freedom 634. The study found that proprioception error has significant difference in effect on injured knee, with $\mathrm{P}<0.03^{*}$.

Conclusion: The study concluded that proprioception error was varied between knee injured and uninjured groups. Proprioception error of knee joint was more among injured male professional footballers compared to the uninjured footballers.

Key words: Professional footballers, proprioception error, photographic analysis, knee injury

Received $05^{\text {th }}$ January 2015, revised $24^{\text {th }}$ January 2015, accepted $02^{\text {nd }}$ February 2015

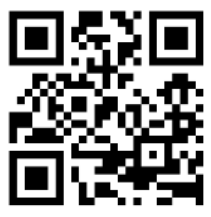

WwW.ijphy.org
DOI: 10.15621/ijphy/2015/v2i1/60042

\footnotetext{
${ }^{2}$ Faculty of General Adapted,

Physical Education and Yoga,

Ramakrishna Mission Vivekananda University,

Coimbatore, India.
}

\section{CORRESPONDING AUTHOR}

${ }^{1}$ Jibi Paul, MPT, (PhD)

Department of Physiotherapy,

School of Health Sciences,

KPJ Healthcare University College,

Kota Seriemas, Nilai, Malaysia 


\section{INTRODUCTION}

Football is one of the most popular sports in the world. The location and nature of injuries are common in knee and ankle joints as per the recorded sports injuries. Proprioception deficits predicted knee injury with $90 \%$ sensitivity and $56 \%$ specificity in female athletes whereas no similar association was apparent in male subjects., ${ }^{1,2}$ Potential relationship of proprioception is considered with knee injury, laxity, activity level, subjective function and age of an individual. . $^{3,4}$ Absence of proprioceptive feedback cannot maintain the arm in a steady posture or execute controlled movements without watching their limbs. ${ }^{6,7,8,9}$ This study is focusing on evaluating the proprioception error on knee injured and uninjured professional footballers. The study has also compared the effect of injured and uninjured knee on proprioception error among male professional footballers.

\section{MATERIALS AND METHODS}

This study was a cross sectional comparative study design. This study included male footballers with medically diagnosed as first and second degree unilateral and bilateral knee injury within five months period with the age group between 20 and 35 years for the year 2013. Total hundred and six (106) subjects were selected for the study. Hundred and eighteen injured and ninety four uninjured knee samples were analysed for this study. The subjects were selected from registered football associations of Kuala Lampur, Petaling Jaya, Port Clang, Subang Jaya, Puchong, Selangor and Sungai Pelek in Malaysia. Medically diagnosed knee injured (unilateral and bilateral) footballers within 20 weeks prior to the investigation were selected in this study. Professional football players with minimum one year experience were included for this study. Any subjects with trauma or pathology of lower limb were excluded from the study. Injured and uninjured knee were divided into two groups for analysis of this study.

Active proprioception error for both knee joints was evaluated by photo graphic analysis method. Proprioception was measured at inner range (0-20), middle range (70-90) and outer range (120-140) for the right and left knee. The subject was positioned comfortably in prone lying to see the joint position and exposed the area to be evaluated. Three markings were made by placing an adhesive marker at lateral epicondyle of femur, tibial malleoli and 10 centimetres above lateral epicondyle of femur in the line of greater trochanter of femur. The digital camera was positioned 1.5 metre away perpendicular to the knee joint. ${ }^{10,11,12,13}$

Therapist moved the knee joint 3 to 4 times and stopped in a targeted angle and took the photograph of the joint position. The participant was then asked to memorise the same position. Later, the participant was blind folded and asked to do three-four times complete flexion and extension and the joint back at the targeted angle of the joint Photograph was taken again to check the joint position. This is done for all the three ranges (inner, middle and outer) of movement for both knees of lower limbs. The photographs were analysed using image tool software and the difference in range of movement (Proprioception error) entered as the reposition error.

\section{Statistical Analysis}

Data analysis was conducted to find out the proprioception error among injured and uninjured groups.Compared the proprioception error of injured and uninjured knee joint. Independent $t^{\prime}$ test used to find out the significant difference between the groups. P value $<0.05$ has considered as significant difference in proprioception error among knee injured and uninjured professional football players.

\section{RESULT}

Comparative study was conducted using independent $t^{\prime}$ test for proprioception error between knees injured and uninjured groups. The means of knee injured and uninjured groups were 6.08 and 5.55 respectively. The standard deviation was 3.23 and 2.63 respectively for injured and uninjured group. Calculated t' value for the study was 2.21 with degree of freedom 634 . The study found that proprioception has significant effect on knee injury, with $P<0.03^{*}$, which has presented in table 1.

Table-1 Proprioception error between injured and uninjured knee joint

\begin{tabular}{c|c|c|c|c|}
$\begin{array}{c}\text { Proprioception error of } \\
\text { injured knee } \\
\text { Mean } \pm \text { SD) }\end{array}$ & $\begin{array}{c}\text { Proprioception error of } \\
\text { uninjured knee } \\
\text { (Mean } \pm \text { SD) }\end{array}$ & T value & Df & P-Value \\
\hline $6.08 \pm 3.23$ & $5.55 \pm 2.63$ & 2.21 & 634 & $P<0.03^{*}$
\end{tabular}


The above table shows the mean, standard deviation (SD), degree of freedom (df) and 't' value of proprioception error for injured and uninjured knee joints among professional male footballers. The proprioception error mean of knee injured group is more than that of knee uninjured groups, with 6.26 and 5.64 respectively and calculated $\mathrm{t}^{\prime}$ value is 2.21 .

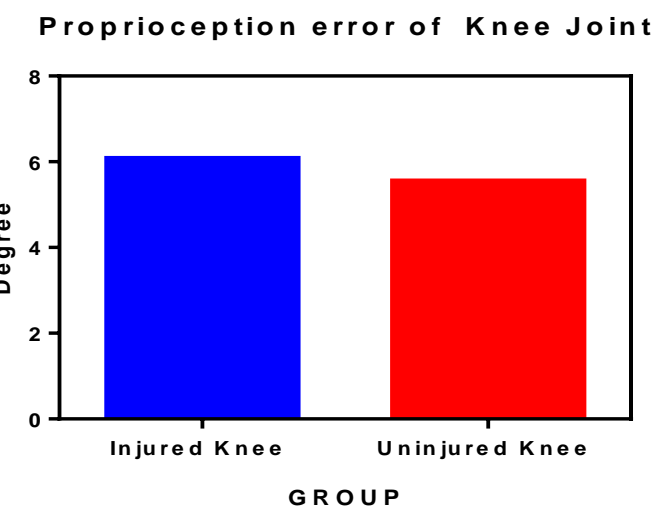

Figure-1 Proprioception error between injured and uninjured knee joints

The above graphical representation shows the mean difference of proprioception error between injured and uninjured knee joints among professional male footballers.

\section{DISCUSSION}

Football is a contact sport and running game that involves periods of continuous physical activity, interspersed with periods of high-intensity activity, including unexpected, explosive and agile movements with heavy physical contacts. The game features contribute to the high risk of injury. Potential relationship of proprioception is considered with knee injury, laxity, activity level, subjective function and age of an individual. Proprioceptive defect of knee joint has been seen in football players with more meniscal injuries than with anterior cruciate ligament (ACL) rupture alone. . $^{4,15,16,17,18}$

Proprioceptive training reduces lower extremity injuries in young soccer players. A randomized controlled trial performed on young soccer player's Young championship of the first Greek division (2001-2002). Two teams were the experimental group $(N=50)$ and the other two the control group $(N=50)$, total 100 young soccer players from four different soccer teams. Proprioception training program were given for twice a week with 20 minute sessions. The application of a specific balance training program on healthy young athletes is proposed in order to improve their proprioception ability and prevent lower limb injuries. The results revealed that proprioception is less in injured athletes and special training can improve proprioception thereby can prevent injuries. ${ }^{19}$

Non-contact anterior cruciate ligament injuries in soccer players trained with prevention program had reduced injury rates at Lower extremity by plyometric, dynamic balance training. Proprioceptive training had prevented knee ligament injuries among soccer players; the mean absolute proprioception error of the intervention team at the baseline was $9.00^{\circ} \pm 6.14^{\circ}$ which decreased significantly after four months of intervention $4.00^{\circ} \pm 3.48^{\circ}$; this shows that proprioception error would be less in uninjured players. ${ }^{20}$

Lower limb Injury prevention training program included proprioceptive and neuromuscular training on prevention of knee and ankle injuries found that the effect of sprain was the most frequent diagnosis in both groups with 11 ankle sprains in the control group and 7 ankle sprains in the intervention group. The knee was the second frequent injury site. In the control group 5 of all knee injuries were anterior cruciate ligament (ACL) ruptures in comparison with one in the intervention group. This study concluded that reduced proprioception error has prevented knee and ankle injuries among female European team handball players. $^{21}$

In this investigation the mean ages of professional footballers were $27.5 \pm 7.5$ and professional experience was $5.93 \pm 4.79$. Proprioception error of injured knee was more compared to the uninjured knee among male professional footballers. Many studies have proved that proprioception error is associated with injury of knee joint. In respect to this issue, footballers are required to trained well to prevent knee injuries.

\section{CONCLUSION}

The study concluded that proprioception error has significant effect on knee injury. Proprioception error of knee joint was more among injured male professional footballers than uninjured footballers.

\section{REFERENCE}

1. Corrigan J P. Cashman W F. Brady M P. Proprioception $1 \mathrm{n}$ the cruciate deficient knee J Bone Joint Surg Br. 1992; 74 (2): 247-50.

2. David Robert, Gert. Anderson and Thomas Frieden, acta. orthp. Scand 2004; 75(1):78-83.

3. Friden T. Roberts D, et.al. Proprioception in acute knee ligament injury; a longitudinal study on 16 consecutive patients J. Orthop. Res 1997; 15 (5); 637-44.

4. Friden T. Robert D. et.al. Proprioceptive defects after an anterior cruciate ligament 
rupture- the relation to associated anatomical lesion and subjective knee function, Knee Surg. Spots Traumatol Arthrosc 1999;7 (4) ,226-31.

5. Fischer-Rasmussen T. Jensen $P$ E. Proprioceptive sensitivity and performance in anterior cruciate ligament-deficient knee joint, Scand J Med Sci Sports 2000; 10 (2): 85-9.

6. Fremerey R.et.al. Proprioception after rehabilitation and reconstruction in knees with deficiency of the anterior cruciate ligament: a prospective longitudinal study J. Bone Joint Surg Br 2000; 82 (6): 801-6.

7. Friden T. Roberts D, et.al. Proprioception in the nearly extended knee, Measurements of position and movement in healthy individual and symptomatic anterior cruciate ligament injured patients. Knee Surg Spots Traumatol Arthrosc 1996; 4 (4) 217-24.

8. Skinner H B., Barrack, R L., Cook S D. Agerelated decline in proprioception Clin Orthop 1984; 184:208-11.

9. Zazulak BT, et.al. The effects of core proprioception on knee injury: a prospective biomechanical-epidemiological study. Am. J Sports Med 2007; 35: 368-373.

10. Nasseri N, et.al. Reliability and accuracy of joint position Sense measurement in the laboratory and Clinic; utilising a new system, Acta Medica Iranica 2007; Vol. 45, No. 5

11. Marks R, et. al. proprioceptive sensibility in women with normal and osteoarthritic knee joints, Clin. heumatol. 1993; 12(2):170-175.

12. Marks $R$, the reliability of knee position sense measurements in healthy women, Physiother. Can; 46(1):37-41(1994)
13. Skinner HB, et.al, Barrack RL. Effect of fatigue on joint position sense of the knee, J. Orthop Res1986; 4:112-118.

14. Barrack RL, et.al. Proprioception in the anterior cruciate deficient knee. Am. J. Sports Med 1989; 17:1-6.

15. Barrett DS. Proprioception and function after anterior cruciate reconstruction. J. Bone Joint Surg Br 1991; 73: 833-837.

16. Johansson $\mathrm{H}$, et.al. Receptors in the knee joint and their role in the biomechanics of the joint. Crit. Rev Biomed. Eng. 1991; 18:341-368.

17. Lephart SM, et.al. Proprioception following anterior cruciate ligament reconstruction. J. Sports. Rehab 1992; 1:188-196.

18. Kaplan FS, et.al. Age-related changes in proprioception and sensation of joint position. Acta Orthop Scand. 1985; 56:72-74.

19. Malliou, et. al. Proprioceptive training (balance exercises) reduces lower extremity injuries in young soccer players, Journal of Back and Musculoskeletal Rehabilitation 2004;17(34):101-104.

20. G.Panics et. al. Effect of proprioception training on knee joint position sense in female team handball players, British journal of sports medicine 2008; 42:6,472-476.

21. Wolf Petersen et al. A controlled prospective case control study of a prevention training program in female team handball players: the German experience, Arch Orthop Trauma Surg 2005; 125: 614-621.

\section{Citation}

Jibi Paul, Dr. M S Nagarajan. (2015). COMPARISON OF PROPRIOCEPTION IN INJURED AND UNINJURED KNEE JOINTS AMONG MALE PROFESSIONAL FOOTBALLERS. International Journal of Physiotherapy, 2(1), 361-364. 